OPEN ACCESS

Edited by:

Chang H. Kim,

Purdue University, United States

Reviewed by:

Tian Wang,

University of Texas Medical Branch,

United States

Francesca Gilli,

Geisel School of Medicine, Dartmouth

College, United States

*Correspondence:

Byung S. Kim

bskim@northwestern.edu

${ }^{\dagger}$ Present Address:

Min H. Kang,

Department of Ophthalmology, Case

Western Reserve University,

Cleveland, $\mathrm{OH}$, United States

Young $H$. Jin,

Korean Medicine Application Center, Korean Institute of Oriental Medicine,

Daegu, South Korea

Received: 31 October 2017 Accepted: 09 January 2018 Published: 23 January 2018

Citation: Kang MH, Jin YH and Kim BS (2018) Effects of Keratinocyte-Derived Cytokine (CXCL-1) on the

Development of Theiler's Virus-Induced Demyelinating Disease. Front. Cell. Infect. Microbiol. 8:9. doi: 10.3389/fcimb.2018.00009

\section{Effects of Keratinocyte-Derived Cytokine (CXCL-1) on the Development of Theiler's Virus-Induced Demyelinating Disease}

\author{
Min H. Kang ${ }^{\dagger}$, Young H. Jin ${ }^{\dagger}$ and Byung S. Kim* \\ Department of Microbiology-Immunology, Northwestern University Medical School, Chicago, IL, United States
}

CXCL-1, also called keratinocyte-derived cytokine $(\mathrm{KC})$, is a predominant chemokine produced in glial cells upon infection with Theiler's murine encephalomyelitis virus (TMEV). In this study, we assessed the role of $\mathrm{KC}$ in the development of TMEV-induced demyelinating disease by utilizing polyclonal anti-KC antibodies as well as KC-expressing recombinant TMEV. Our results indicate that the level of $\mathrm{KC}$ produced after infection with TMEV or stimulation with various TLRs is significantly higher in various cells from susceptible SJL mice compared to those in cells from resistant B6 mice. SJL mice treated with rabbit anti-KC antibodies displayed accelerated development of TMEV-induced demyelinating disease, elevated viral loads in the CNS and decreased antiviral T cell responses. In addition, infection of susceptible SJL mice with recombinant KC-TMEV produced biologically active $\mathrm{KC}$, which resulted in the accelerated pathogenesis of demyelinating disease and elevated $T$ cell responses to viral antigens compared to mice infected with control recombinant HEL-TMEV. These results strongly suggest that both the lack of $\mathrm{KC}$ during TMEV infection and the excessive presence of the chemokine promote the pathogenesis of demyelinating disease. Therefore, a balance in the level of KC during TMEV infection appears to be critically important in controlling the pathogenesis of demyelinating disease.

Keywords: CXCL-1 chemokine, keratinocyte-derived cytokine, infection and replication, central nervous system, recombinant TMEV

\section{INTRODUCTION}

Theiler's murine encephalomyelitis virus (TMEV)-induced demyelinating disease in mice has been extensively investigated as a relevant animal model for multiple sclerosis (MS). Infection of susceptible SJL/J mice with TMEV causes the development of clinical signs similar to MS (Leibowitz and Rodriguez, 1983; Dal Canto et al., 1996; Kim et al., 2001). Immune responses to viral and/or CNS autoantigens have been implicated in the development of TMEV-induced demyelinating disease (Lipton and Dal Canto, 1976; Clatch et al., 1987; Yauch et al., 1998). TMEV has a single-stranded RNA genome of $\sim 8 \mathrm{~kb}$ with positive polarity and belongs to the genus

Abbreviations: CNS, central nervous system; KC, keratinocyte-derived cytokine; dpi, days post-infection; CNS, central nervous system; TMEV, Theiler's murine encephalomyelitis virus; TMEV-IDD, TMEV-induced demyelinating disease. KCTMEV, KC-expressing recombinant TMEV; HEL-TMEV, hen-egg lysozyme-expressing TMEV; PCR, polymerase chain reaction; $\mathrm{PFU}$, plaque-forming unit; $\mathrm{MOI}$, multiplicity of infection. 
Cardiovirus of the Picornaviridae family (Lehrich et al., 1976; Lorch et al., 1981). TMEV infects various glial cells, antigen-presenting macrophages and dendritic cells (Aubert et al., 1987; Zheng et al., 2001; Lipton et al., 2005; Jin et al., 2007; Hou et al., 2009). TMEV infection activates the production of various proinflammatory cytokines and chemokines in these cell types (Palma and Kim, 2001, 2004). These proinflammatory chemokines and cytokines consequently contribute to cellular infiltration into the CNS and further activation of infiltrated inflammatory immune cells, eventually leading to the development and progression of virus-induced demyelinating disease (Kim et al., 2001, 2012; Hou et al., 2009).

Infection of cells with TMEV activates the production of various cytokines and chemokines via TLR- and melanoma differentiation-associated gene 5 (MDA5)-dependent pathways (So et al., 2006; So and Kim, 2009; Jin et al., 2012). Although an excessive level of TLR3 signaling contributes to the pathogenesis of the disease, the presence of the TLR3 signal is required to protect the host from chronic viral infections (Jin et al., 2011). These results suggest that the level of activating signaling and downstream cytokine production is critically important in the protection or the pathogenesis of demyelinating disease. In fact, the presence of high levels of IL-1 or type I IFNs, which are downstream products of such activations, play a pathogenic role. However, the lack of these cytokines promotes viral persistence and manifestation of the disease (Jin et al., 2010; Kim et al., 2012). Similarly, excessive levels of IL-6, which has important roles in $\mathrm{B}$ cell development and $\mathrm{T}$ cell responses, exert a potent effect on the pathogenesis of TMEV-induced demyelinating disease by promoting Th17 responses (Hou et al., 2009). Therefore, understanding the roles of such cytokines and chemokines produced upon viral infections in the protection and/or pathogenesis of chronic viral diseases is of paramount importance.

Very little attention has been given to the role of chemokines produced upon viral infections in the protection and/or pathogenesis of viral diseases. The major function of chemokines is to attract various cells and promote the migration of cells to certain sites. It has been long known that TMEV infection, similar to other viral infections, induces production of various chemokines in different types of glial cells and antigen-presenting cells such as DCs and macrophages (Palma and Kim, 2001, 2004). KC (keratinocyte-derived cytokine), an innate chemokine encoded by a short gene $(<250 \mathrm{bp})$, is the predominant chemokine produced by various glial cell types after infection with TMEV (Palma and Kim, 2004; Rubio and Sanz-Rodriguez, 2007). The level of KC secreted by astrocytes $6 \mathrm{~h}$ after TMEV infection was more than 20-fold higher compared to that of MCP-1 and MIP- $1 \alpha$ (Palma and Kim, 2004). KC is also known as GRO1 oncogene, GRO $\alpha$, or CXCL-1. It is known to be associated with infiltration of neutrophils and other inflammatory cells (Zhou et al., 2003) that are believed to contribute to the pathogenesis of TMEV-induced demyelinating disease in the CNS (Aubert et al., 1987; Zheng et al., 2001; Jin et al., 2007, 2015). It has also previously shown that the lack of $\mathrm{KC}$ and sustained presence of KC amplifies the development of mouse hepatitis virus-induced demyelinating disease (Hosking et al., 2009; Marro et al., 2016). In addition, $\mathrm{KC}$ signaling via CXCR2 is also associated with the number and positioning of oligodendrocytes during the development of the spinal cord (Robinson et al., 1998; Tsai et al., 2002). Furthermore, KC signaling appears to associate with neuroprotection (Omari et al., 2009) or pathogenesis in different MS models (Kerstetter et al., 2009). However, the underlying mechanisms for the effects of $\mathrm{KC}$ associated with viral infection on the development of TMEV-induced demyelinating disease remain unclear.

In this study, we assessed the role of $\mathrm{KC}$ in the development of TMEV-induced demyelinating disease by utilizing polyclonal anti-KC antibodies and $\mathrm{KC}$-expressing recombinant TMEV (KCTMEV). Our results indicate that the level of KC produced after infection with TMEV or stimulation with various TLRs is significantly higher in cells from susceptible SJL mice compared to those in cells from resistant B6 mice, suggesting an important role of $\mathrm{KC}$ in the susceptible mice. SJL mice treated with rabbit anti-KC antibodies displayed accelerated development of TMEVinduced demyelinating disease, reduced cellular infiltration to the CNS and decreased levels of antiviral $\mathrm{T}$ cell responses, accompanied with increased viral loads in the CNS. In addition, we generated a stable recombinant $\mathrm{KC}$-expressing TMEV strain to investigate the role of chemokine production at the site of TMEV infection during the pathogenesis of demyelinating disease. KC produced in the non-mouse cells (BHK) after infection with the recombinant KC-TMEV yielded a biologically active chemokine. The levels of chemokine produced in mouse cells infected with TMEV were significantly higher than that in cells infected with control HEL-TMEV infection. In addition, infection of susceptible SJL mice with KC-TMEV resulted in accelerated pathogenesis of demyelinating disease along with elevated levels of both pathogenic and protective $\mathrm{T}$ cell responses to viral antigens compared to mice infected with control HELTMEV. These results suggest that both the lack of KC during TMEV infection and the excessive presence at the site of infection promote the pathogenesis of demyelinating disease. Therefore, a balance in the KC level appears to be critically important in controlling the pathogenesis of TMEV-induced demyelinating disease.

\section{METHODS}

\section{Animals}

Female SJL/J and C57BL/6 mice (4- to 6-weeks-old) were purchased from Harlan (Indianapolis, IN). The mice were housed in the animal facility of the Northwestern University Medical School and used following protocols approved by the Institutional Animal Care and Use Committee.

\section{Preparation of Macrophages and Astrocytes}

Peripheral macrophages were obtained from the adherent population of peritoneal exudates of adult mice. The majority (>90\%) of the adherent cells were $\mathrm{CD} 45^{+} \mathrm{CD} 11 \mathrm{~b}{ }^{+}$. Primary astrocytes were derived from 0 - to 3-day-old neonates by using differential shaking (Skias et al., 1987). The cell preparations 
were at least $90 \%$ pure, as confirmed by staining with antibodies specific for the astrocyte marker GFAP (Dako, California).

\section{In Vitro Stimulation and Viral Infection}

For in vitro viral infection, cells were washed and subsequently incubated in infection media (DMEM supplemented with $0.1 \%$ bovine serum albumin) with the BeAn strain of TMEV at various multiplicity of infection (MOI). Macrophages and astrocytes derived from susceptible SJL and resistant B6 mice $\left(5 \times 10^{5} /\right.$ well $)$ in six-well plates were infected with TMEV (at MOI $=1,5$, or 10 ) in triplicates for $24 \mathrm{~h}$. In addition, macrophages from MyD88deficient (009088/MyD88 ${ }^{\text {tm1.1Defr }}$, Jackson laboratory) or control B6 mice were similarly stimulated with TMEV infection (MOI = 10 or 50), or treatment with TLR ligands or TNF- $\alpha$ for $24 \mathrm{~h}$.

\section{Virus Preparation and Assessment}

The BeAn strain of TMEV was expanded in BHK cells, which were grown in Dulbecco's modified Eagle's medium (ThermoFisher, Waltham, MA) supplemented with $7.5 \%$ donor calf serum (Yauch et al., 1998). Viral titer was determined using a standard plaque assay on BHK monolayers (Pullen et al., 1995).

\section{Assessment of Clinical Signs}

Approximately $30 \mu \mathrm{l}$ of TMEV was injected into the right hemisphere of 5- to 7-week-old mice anesthetized with isoflurane. SJL mice were intraperitoneally injected with polyclonal rabbit anti-KC IgG antibodies $(100 \mu \mathrm{g})$ or control IgG from unimmunized rabbits (Cellscience, Canton, MA) at $-1,2$, and $6 \mathrm{dpi}$ of TMEV ( $\left.1 \times 10^{6} \mathrm{PFU}\right)$. For recombinant TMEV study, SJL mice were infected with $3 \times 10^{6}$ PFU KCTMEV or HEL-TMEV. The clinical symptoms of the disease were assessed weekly using the following grading scale: grade $0=$ no clinical signs; grade $1=$ mild waddling gait; grade $2=$ moderate waddling gait and hind limb paresis; grade $3=$ severe hind limb paralysis; grade $4=$ severe hind limb paralysis and loss of righting reflex; and grade $5=$ death.

\section{Elisa}

The levels of cytokines/chemokines in the culture supernatants in 96-well plates after TMEV infection or mock infection with BHK lysates were assessed using specific ELISA kits. Mouse KC (CXCL-1), mouse IFN- $\gamma$, and IL-17 kits were purchased from BD Biosciences (San Diego, CA). The cytokine levels in splenic culture supernatants stimulated with viral epitopes for $72 \mathrm{~h}$ were assessed according to the manufacturer's instructions. Briefly, diluted samples were incubated for $2 \mathrm{~h}$ with the platebound capture antibodies after blocking for $1 \mathrm{~h}$. The expression levels of the cytokines were visualized using HRP-conjugated detection antibodies in the presence of the HRP substrate tetramethylbenzidine (TMB; BioFX Laboratories, Owings Mills, MD, USA). The plates were read at $450 \mathrm{~nm}$ using a microplate reader.

\section{Histopathological Examinations}

At 35 days post-infection (dpi), SJL mice treated with anti$\mathrm{KC}$ antibody or control antibody were perfused via intracardiac puncture with $50 \mathrm{ml}$ of cold PBS. Brains and spinal cords were fixed in $4 \%$ formalin in PBS for 4 days and then embedded in paraffin for sectioning and staining. Paraffin-processed brains and spinal cords were sectioned at $6 \mu \mathrm{m}$ thickness. Sections from each animal were deparaffinized, rehydrated, and evaluated separately by Luxol Fast Blue (LFB) staining for axonal demyelination and by hematoxylin and eosin (H\&E) staining for inflammatory infiltrates. The slides were examined using Leica DMR light microscope and images were captured using AxioCam MRc camera and AxioVision imaging software.

\section{Preparation of CNS Mononuclear Cells}

Brains and spinal cords were removed from mice after perfusion with Hank's balanced salt solution (HBSS) through the left ventricle. The tissues were forced through a steel mesh to prepare single-cell suspensions and incubated at $37^{\circ} \mathrm{C}$ for $45 \mathrm{~min}$ in PBS containing $250 \mu \mathrm{g} / \mathrm{ml}$ of collagenase type 4 (Worthington Biochemical Corp., Lakewood, NJ). A continuous 100\% Percoll gradient (Pharmacia, Piscataway, NJ) was centrifuged at 27,000 g for $30 \mathrm{~min}$ to enrich for CNS-infiltrating mononuclear cells.

\section{Flow Cytometry Determinations}

CNS mononuclear cells from mice were cultured in plates coated with either anti-CD3 plus anti-CD28 antibodies or viral epitope peptides in the presence of Golgi-Plug for $6 \mathrm{~h}$ at $37^{\circ} \mathrm{C}$. The cells were then incubated in $50 \mu \mathrm{l}$ of $2.4 \mathrm{G} 2$ hybridoma (American Type Culture Collection) supernatant for $30 \mathrm{~min}$ at $4^{\circ} \mathrm{C}$ to block the $\mathrm{Fc}$ receptors. The cells were incubated for an additional $30 \mathrm{~min}$ at $4^{\circ} \mathrm{C}$ in the presence of allophycocyanin-conjugated anti-CD8 (clone 53-6.7) or antiCD4 (GK1.5) antibodies diluted in $50 \mu$ l of Fc-block (2.4G2 supernatant). After two washes, intracellular IFN- $\gamma$ staining was performed according to the manufacturer's instructions (BD Pharmingen) using phycoerythrin-labeled rat monoclonal antiIFN- $\gamma$ antibody (XMG1.2). The cells were analyzed on a Becton Dickinson FACSCalibur flow cytometer.

\section{Generation of KC-TMEV and HEL-TMEV Constructs}

The Cla I/dL23 TMEV construct, which has 23 central codons of the TMEV leader replaced with the Cla I restriction site (Calenoff et al., 1995), was obtained from Dr. Calenof of Northwestern University at Northwestern University Medical School, Chicago, IL. The sense PCR primer containing the Cla I site with the $5^{\prime}$

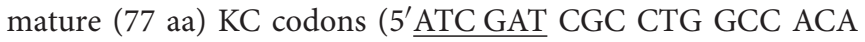
GGG GCG $3^{\prime}$ ) and anti-sense primer containing the Cla I site with the $3^{\prime}$ end of KC ( $5^{\prime}$ ATC GAT CTT GGG GAC ACC TTT TAG $3^{\prime}$ ) were used to amplify Cla I-KC cDNA from mRNA preparations of LPS-activated macrophages. The amplified Cla IKC cDNA was ligated into the Cla I site of dL23 TMEV. Similarly, a short form of the hen egg lysozyme ( $5^{\prime} \sim 220$ bp of HEL) was amplified with Cla I-HEL primers ( $5^{\prime}$ ATC GAT AAA GTC TTT GGA CGA TGT $3^{\prime}$ and $5^{\prime}$ ATC GAT TGG GGT CCT GCC ATC GTT $3^{\prime}$ ) from hen embryonic library and cloned into the Cla I site of dL23 TMEV. This HEL-TMEV was used as the control for KC-TMEV. 


\section{Western Blot Analysis}

The uninfected control and virus-infected BHK cells were disrupted using lysis buffer (Tris-buffered saline with $1 \%$ Triton X-100). The samples (10 $\mu \gamma /$ lane $)$ were separated by electrophoresis on $12 \%$ sodium dodecyl sulfate (SDS) polyacrylamide gels, transferred onto nitrocellulose membrane (Amersham Pharmacia Biotech, Piscataway, NJ), and then treated with polyclonal rabbit antibodies specific for mouse $\mathrm{KC}$ (IBL-America, Minneapolis, MN55432). Horseradish peroxidase (HRP)-conjugated antibodies were subsequently applied as the secondary antibodies. Specific protein levels were visualized using the ECL kit (Amersham Biosciences, Piscataway, NJ).

\section{Measurement of Neutrophil Migration}

Peripheral blood cells from naïve green fluorescent protein (GFP)-expressing C57BL/6 Tg mice [C57BL/6 Tg(CAG-EGFP), Jackson Laboratories, Maine] were used as the source of neutrophils. After removal of red blood cells using red blood cell lysing buffer (R7757, Sigma Aldrich), the cells were further purified using negative magnetic cell sorting, which utilizes the antibodies for CD2, CD5, CD45R, F4/80, and ICAM1 , as previously described (Cotter et al., 2001; Yona et al., 2010). A standard micropore filter assay using Boyden chambers was performed (Gho et al., 1999). Briefly, the lower well of the chamber of a 12-well plate was filled with conditioned media from BHK monolayers mock-infected and infected with TMEV, KC-TMEV, or HEL-TMEV for $24 \mathrm{~h}$ at $10 \mathrm{MOI}$. The upper chambers containing transwells ( $8 \mu \mathrm{m}$ pore size, Corning, \#353182) were placed on the conditioned media. The isolated neutrophils were added to the transwells and incubated in 5\% $\mathrm{CO}_{2}$ for $3 \mathrm{~h}$ at $37^{\circ} \mathrm{C}$. The number of cells on the outside of the transwell membrane were enumerated using fluorescence microscopy.

\section{Statistical Analysis}

The data are shown as the mean $\pm S D$ of either 2-3 independent experiments or as a representative from at least three independent experiments. The differences in the mean values were determined by Student's $t$-test using the InStat Program (GraphPad Software, San Diego, CA, USA), unless otherwise indicated. Multiple group comparisons were done by one-way analysis of variance (ANOVA) with Tukey-Kramer posthoc analysis. $P$-values of $<0.05$ were considered to be statistically significant.

\section{RESULTS}

\section{Higher Production of KC (CXCL-1) in Cells Derived from Susceptible SJL Mice Compared to Those from Resistant B6 Mice}

To determine whether the levels of $\mathrm{KC}$ induction from susceptible SJL and resistant C57BL/6 mice are different after TMEV infection in cells, the levels of $\mathrm{KC}$ proteins produced in peripheral macrophages and primary neonatal astrocytes derived from these mice were compared using specific ELISA

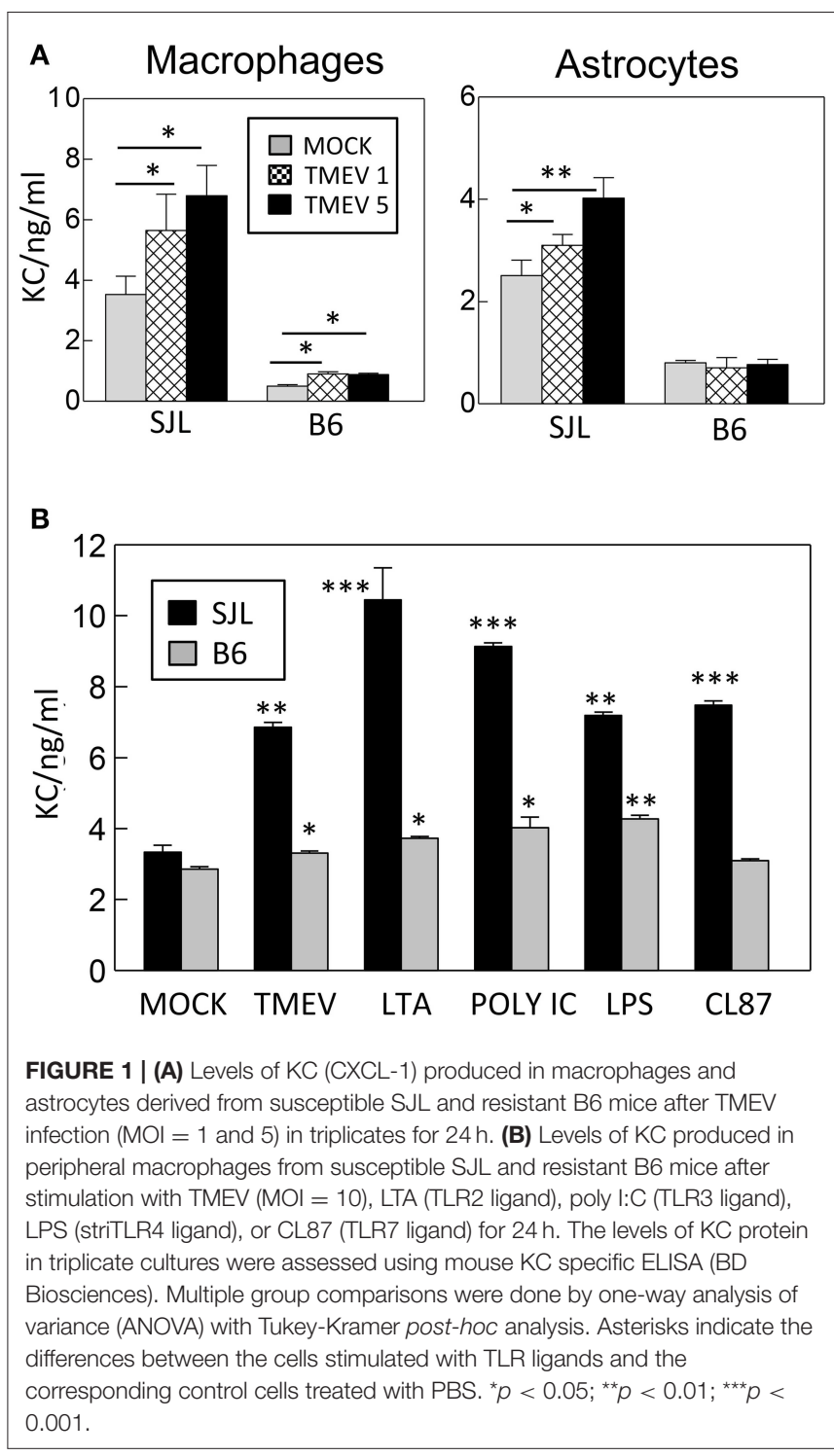

(Figure 1). Interestingly, the background levels of KC produced without TMEV infection were significantly high ( $>2$-fold; $p$ $<0.01)$ in both cell types from SJL mice compared to those from B6 mice (Figure 1A). In addition, the increase in $\mathrm{KC}$ production was greater in the cells after TMEV infection; consequently, the overall $\mathrm{KC}$ level was significantly higher (>3-fold; $p<0.01$ ) in the SJL mice compared to B6 mice. Furthermore, the levels of KC production were much higher $(p<0.01)$ in macrophages from SJL mice compared to those from B6 mice after stimulation with different TLR ligands; LTA for TLR2, poly I:C for TLR3, LPS for TLR4, and CL87 for TLR7 (Figure 1B). Therefore, much higher levels of $\mathrm{KC}$ are produced in cells from susceptible SJL mice in response to various stimulants compared to cells from resistant B6 mice. These differences in KC production levels after TMEV infection may affect cellular migration and pathogenesis of demyelinating disease. 


\section{MyD88-Dependent Activation of KC Production following Infection with TMEV}

It has previously been shown that $\mathrm{KC}$ production is dependent on the presence of MyD88 (Farnand et al., 2011; Guerrero et al., 2012). We examined the requirement of MyD88 in the production of KC and IL- 6 after TMEV infection in macrophages derived from MyD88-deficient and control B6 mice (Figure 2). Both KC and IL-6 mRNA levels were significantly elevated ( $>3$ fold) in macrophages from control B6 mice after treatment with a TLR3 ligand poly I:C or infection with TMEV (Figure 2A). In contrast, $\mathrm{KC}$ mRNA levels produced in MyD88-deficient macrophages after these stimulations were minimal, indicating that the production of $\mathrm{KC}$ is dependent on the presence of MyD88. Interestingly, however, IL-6 mRNA produced in MyD88-deficient macrophages was minimal after stimulation with poly I:C but was comparable to the level of control macrophages after infection with TMEV. Furthermore, KC and IL-6 protein levels assessed using ELISA were consistent with the corresponding mRNA levels in the macrophages after these stimulations (Figure 2B). This confirmed that KC production was completely dependent on the presence of MyD88 following poly I:C treatment or TMEV infection. Therefore, these results suggest that the production of $\mathrm{KC}$ is dependent on the presence of MyD88 but that of IL- 6 is less dependent on MyD88 in the case of TMEV infection. Additionally, the dependence of KC production in the presence of MyD88 was consistent with the production after stimulation with LPS or TNF- $\alpha$ (Figure 2C).

\section{Elevated Pathogenesis of TMEV-Induced Demyelinating Disease in Mice Treated with Anti-KC Antibodies}

Although an excessive level of KC may promote the pathogenesis of the demyelinating disease, a lack of $\mathrm{KC}$ can also result in disease pathogenesis because of the failure to recruit cells that are required to protect against viral infection. To test this possibility, susceptible SJL mice were treated with anti-KC IgG $(n=18)$ or control $\operatorname{IgG}(n=11)$ prior to viral infection and then the development of clinical symptoms and viral load levels were assessed (Figure 3). Treatment with anti-KC antibodies significantly promoted the pathogenesis of demyelinating disease by TMEV $(p<0.003)$ compared to mice treated with control IgG (Figure 3A). Consistently, the anti-KC antibody-treated mice also showed significantly higher levels $(p<0.01)$ of viral loads in the CNS (both brains and spinal cords) throughout the infection period (Figure 3B). Therefore, we showed that the lack of $\mathrm{KC}$ results in the acceleration TMEV-induced disease pathogenesis and higher viral loads in the CNS.

\section{Histopathological Evidence of Higher Demyelination in SJL Mice Treated with Anti-KC Antibody Compared to the Control SJL Mice}

To correlate the development of clinical signs with demyelination in the CNS, histopathological examinations of the spinal cords from both anti-KC antibody-treated or control SJL mice were performed by LFB and $\mathrm{H} \& \mathrm{E}$ staining at $35 \mathrm{dpi}$
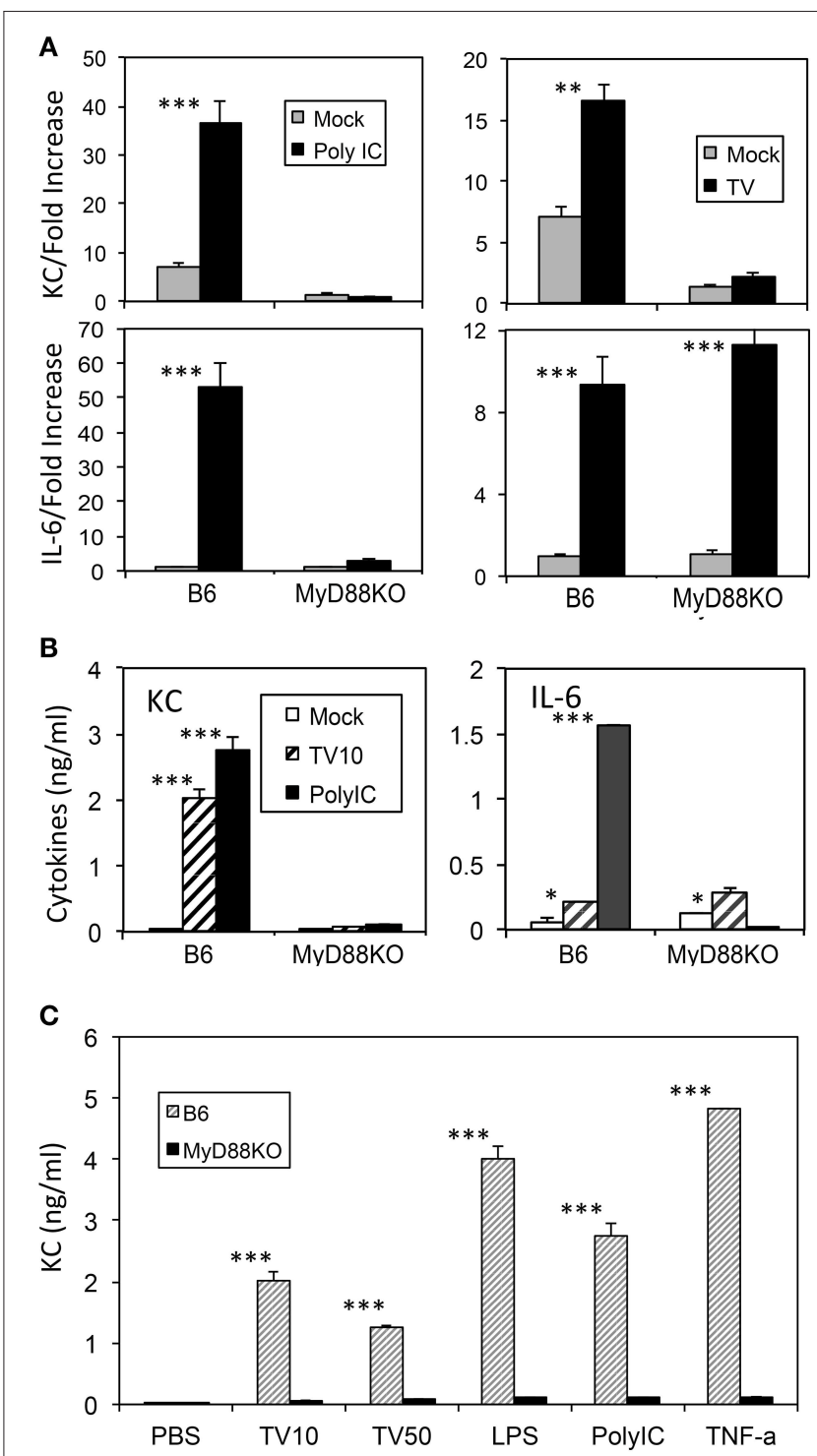

FIGURE 2 | KC levels produced in macrophages with or without MyD88 signaling after stimulation with TMEV, TLR ligands, or TNF- $\alpha$ for $24 \mathrm{~h}$ (A) Levels of $\mathrm{KC}$ and IL-6 mRNAs after TMEV infection in triplicate macrophage cultures from MyD88-deficient and control B6 mice. (B) Levels of KC and IL-6 proteins produced in the macrophages infected with TMEV or poly I:C were assessed using ELISA. (C) Levels of KC produced in the macrophages with or without MyD88 after infection with TMEV (MOI $=10$ or 50$)$ or stimulation with LPS, poly I:C, or TNF- $\alpha$, compared using ELISA. Multiple group comparisons were done by one-way analysis of variance (ANOVA) with Tukey-Kramer post-hoc analysis. ${ }^{\star} p<0.05 ;{ }^{* \star} p<0.01 ;{ }^{* \star *} p<0.001$.

(Figure 4). Irregular vacuolation and moderate demyelination were identified in the white matter of spinal cords in both groups of mice. Lymphocytic infiltrates were also found in the white matter of spinal cord in both groups. However, there were more severe demyelination and infiltration in spinal cords from the anti-KC antibody-treated SJL mice than in control SJL mice, which is consistent with the differential severity of the disease at $35 \mathrm{dpi}$ (Figure 3A). In the anti-KC antibody-treated SJL mice, 

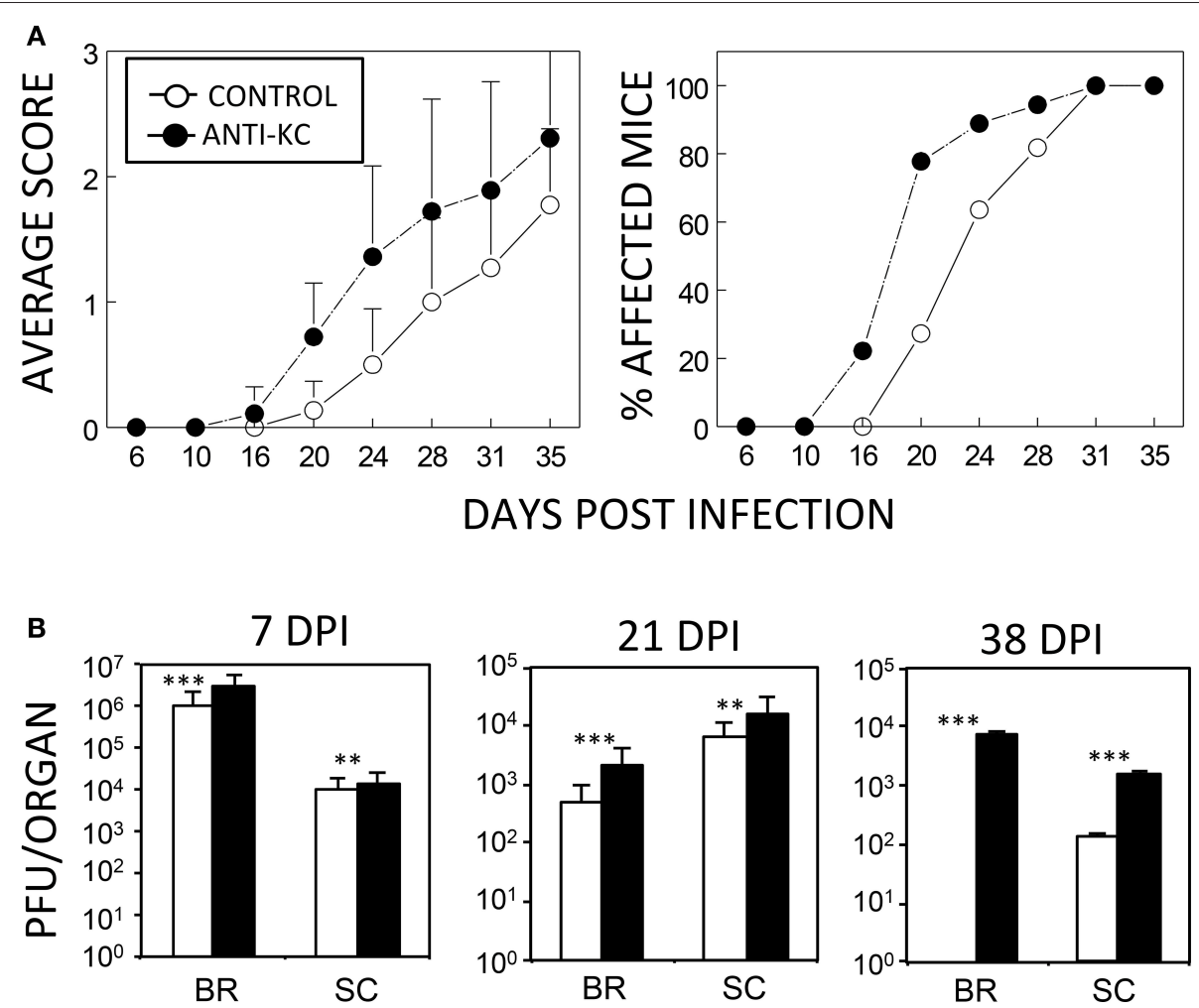

FIGURE 3 | Development of TMEV-induced demyelinating disease in mice treated with anti-KC antibodies or control lgG. (A) Polyclonal rabbit anti-KC antibody or normal rabbit lgG (200 $\mu \mathrm{g} /$ mouse) was intraperitoneally administered into SJL mice $\left(n=18\right.$ and $n=11$, respectively) at $-1,2$, and 6 dpi with TMEV ( $1 \times 10^{6}$ $\mathrm{pfu} / \mathrm{mouse})$. The infected mice were graded for clinical signs as described in the Materials and Methods section. The results were expressed as average clinical scores and percentages of the affected animals at the indicated dpi. The two-tailed $p$-value of average clinical scores between the two groups based on the paired $t$-test during days 16 and 35 post infection was very significant $(p<0.0027)$. (B) Levels of viral loads in the CNS of TMEV-infected anti-KC antibody-treated mice $(n=3)$ and in the control IgG-treated mice $(n=3)$ were measured using the standard plaque assay at 7,21 , and $38 \mathrm{dpi}$. ${ }^{* *} p<0.01 ;{ }^{* \star *} p<0.001$.

both elevated demyelination and infiltration were found in all ventral, lateral, and dorsal areas of the spinal cord and the cellular infiltration was prominent in the demyelinated regions. In contrast, demyelination and infiltration in the control SJL mice were mild and mainly located in the ventral and lateral, but not dorsal spinal cord.

\section{Lower Cellular Infiltration into the CNS of Anti-KC Antibody-Treated SJL Mice Compared to the Control Mice Treated with Normal IgG}

Because $\mathrm{KC}$ is known to affect the migration of neutrophils and other inflammatory cells (Zhou et al., 2003), we assessed the migration levels of $\mathrm{Gr}-1^{+} \mathrm{CD} 45^{+}$cells to the CNS of TMEV-infected mice treated with anti-KC or control antibody using flow cytometry (Figure 5). Gr- $1^{+} \mathrm{CD} 45^{+}$cells include heterogeneous cell population with a myeloid origin (monocytes, neutrophils, and dendritic cells) associated with acute and chronic inflammations (Mazzoni et al., 2002; Soehnlein and Lindbom, 2010). The proportion and the number of Gr$1^{+} \mathrm{CD} 45^{+}$cells were significantly lower $(p<0.05)$ in mice treated with anti-KC antibody compared to the corresponding control mice at early infection (7 dpi) and during the onset of disease (21 dpi), but higher $(p<0.05)$ after the development of disease at 38 dpi (Figures 5A,B). Furthermore, the overall numbers of $\mathrm{CD}_{4} 5^{+}$cells and $\mathrm{CD}^{+}$and $\mathrm{CD}^{+}{ }^{+} \mathrm{T}$ cells were significantly lower in the antibody-treated mice at the early (7 dpi) infection (Figures 5C,D). These results suggest that the reduced level of $\mathrm{KC}$ in the anti-KC antibody-treated mice significantly lowers the initial migration of neutrophils and other inflammatory cells including $\mathrm{CD}^{+}$and $\mathrm{CD} 8^{+} \mathrm{T}$ cells.

\section{Reduced Levels of IFN- $\gamma$-producing CD4 ${ }^{+}$ and $\mathrm{CD}^{+} \mathrm{T}$ cells in the CNS and periphery of Anti-KC Antibody-Treated Mice}

To compare the levels of $\mathrm{T}$ cell responses to the viral determinants in mice treated with anti-KC antibodies and control IgGs, we assessed the levels of $\mathrm{CD}^{+}{ }^{+}$and $\mathrm{CD}^{+}{ }^{+} \mathrm{T}$ cells producing IFN- $\gamma$ in the CNS following stimulation with viral peptides or anti-CD3/anti-CD28 pan-T cell stimulants (Figure 6). The results indicated that the numbers of IFN- $\gamma$-producing $\mathrm{CD}_{4}^{+}$ $\mathrm{T}$ cells in the CNS prior to or at the onset of clinical symptoms ( 7 and $21 \mathrm{dpi}$ ) were significantly lower in mice treated with anti-KC antibodies (Figure 6A). The overall numbers of 


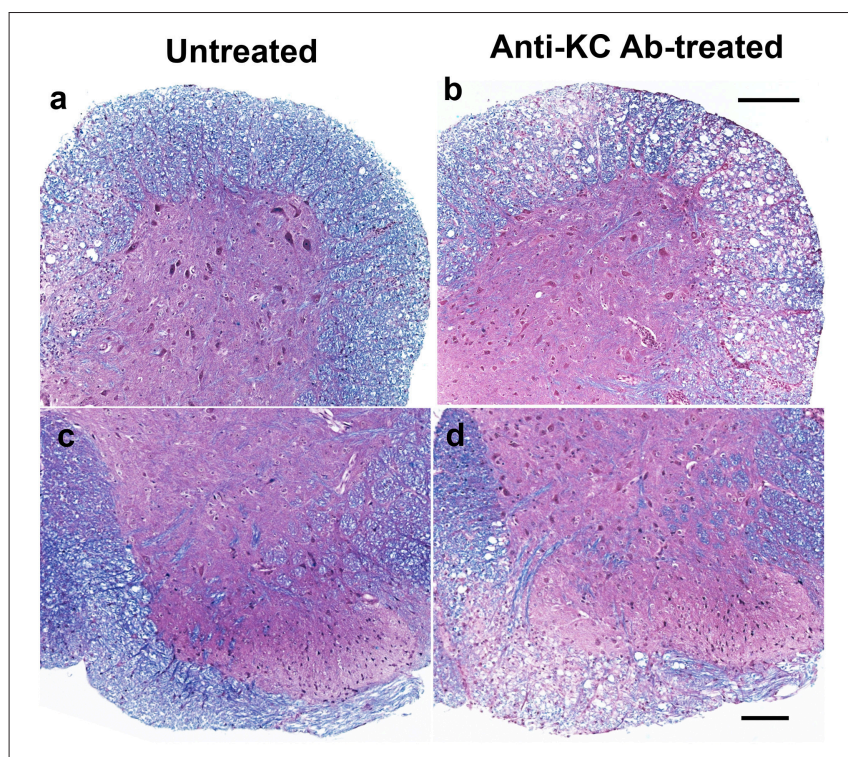

FIGURE 4 | Comparison of histopathology in the spinal cords of anti-KC antibody-treated SJL mice and control SJL mice at $35 \mathrm{dpi}$. Histopathology of the spinal cords of virus-infected mice was examined using LFB and H\&E staining. LFB stain showing myelin in blue in the white matter of spinal cords of anti-KC antibody-treated SJL mice (b,d) and SJL mice (a,c); H\&E stained nuclei in dark blue indicating lymphocyte infiltration in the spinal cords of anti-KC antibody-treated SJL mice (b,d) and SJL mice (a,c); Scale bars a, b $=200 \mu \mathrm{m} ; \mathbf{c}, \mathbf{d}=100 \mu \mathrm{m}$.

IFN- $\gamma$-producing CD8 ${ }^{+}$T cells in the CNS were also significantly lower in the anti-KC antibody-treated mice compared to the control (Figure 6A). These results strongly suggest that the treatment of TMEV-infected mice with anti-KC antibodies lowers the levels of protective IFN- $\gamma$-producing $\mathrm{CD} 4^{+}$and $\mathrm{CD} 8^{+}$ $\mathrm{T}$ cells in the CNS. The levels of IFN- $\gamma$ produced in the splenic cultures of mice treated with anti-KC antibodies at 7 dpi were similarly lower after stimulated with capsid and non-capsid epitope peptides (Figure 6B). Interestingly, however, the levels were higher at $21 \mathrm{dpi}$ in contrast to the CNS. Elevated viral loads in the CNS of anti-KC treated mice due to the inferior protective $\mathrm{T}$ cell responses may result in the higher level of peripheral $\mathrm{T}$ cell response to the virus compared to the control mice.

\section{Production of Functional KC upon Infection of BHK Cells with KC-Expressing Recombinant TMEV}

To determine the potential role of $\mathrm{KC}$ in the pathogenesis of TMEV, we generated recombinant KC-TMEV based on the dL23 TMEV backbone. It was previously shown that recombinant TMEV derived from the dL23 TMEV construct retains its viral pathogenicity in highly susceptible SJL mice (Calenoff et al., 1995). Although there are stability problems associated with large inserts of foreign genes into TMEV genome (Zhang et al., 1995), the recombinant TMEVs expressing the small chemokine (KC) and control (HEL; hen egg lysozyme) genes were very stable. Additionally, no significant deletion of the foreign genes was found during later passages $(>10)$ of the $\mathrm{BHK}$ cell line.

First, we assessed the production of $\mathrm{KC}$ in $\mathrm{BHK}$ cultures infected with $\mathrm{KC}$-TMEV at $24 \mathrm{~h}$ post-infection using Western blotting against rabbit polyclonal antibodies to mouse $\mathrm{KC}$ (Figure 7A). Only the BHK cells infected with KC-TMEV showed detectable levels of mouse KC but not the cells infected with control TMEV or HEL-TMEV. The mouse KC-specific ELISA also indicated that BHK cells mock-infected or infected with control TMEV did not produced significant levels of $\mathrm{KC}$ at both 6 and 24 h post-infection (Figure 7B). In contrast, the levels of $\mathrm{KC}$ were several folds higher $(p<0.01)$ in BHK cells infected with KC-TMEV after 6 and $24 \mathrm{~h}$. These results indicated that the cells infected with KC-TMEV produce higher level of KC than the controls. Further experiments showed that KC was present in culture supernatants as well as in the cell lysates (Figure 7C). Therefore, the high levels of KC produced following KC-TMEV infection might affect the function of both infected cells and adjacent cells.

To further determine the functionality of $\mathrm{KC}$ molecules produced after infection with KC-TMEV, the degree of cell migration in the presence or absence of the chemokine were examined using cell transmigration assays as previously described (Gho et al., 1999). The transmigration of peripheral blood neutrophils that were purified using negative selection was tested to detect whether the cells could migrate through micropore membranes via the $\mathrm{KC}$ gradient produced after $\mathrm{KC}$ TMEV infection (Figure 7D). The peripheral neutrophils were placed on top of Boyden chamber membranes and incubated for $3 \mathrm{~h}$ with serum-free culture supernatants from BHK cells mockinfected, or infected with TMEV, HEL-TMEV, or KC-TMEV for $24 \mathrm{~h}$. The results clearly indicated that the transmigration of neutrophils into the side of the chamber containing supernatants of BHK cells infected with KC-TMEV was significantly increased $(p<0.001)$ compared to that of mock-infected or control HELTMEV or TMEV-infected cells. Therefore, these results strongly suggest that the $\mathrm{KC}$ molecules produced following infection with recombinant $\mathrm{KC}-\mathrm{TMEV}$ are biologically active in promoting cellular migration.

\section{Elevated Pathogenesis of Demyelinating Disease after KC-TMEV infection}

To further determine the role of $\mathrm{KC}$ produced during $\mathrm{KC}$ TMEV infection in the pathogenesis of demyelinating disease, we compared the course of the disease development following infection of SJL mice ( $n=10$ and $n=9$, respectively) with KCTMEV and control HEL-TMEV (Figure 8A). The development of demyelinating disease after infection with KC-TMEV was significantly accelerated $(p<0.001)$ during the course of 50 days compared to mice infected with HEL-TMEV. Therefore, the presence of an elevated level of $\mathrm{KC}$ during viral infection appears to play an important pathogenic role in the development of demyelinating disease.

We further compared the levels of $\mathrm{CD}^{+}$and $\mathrm{CD}^{+} \mathrm{T}$ cells, and $\mathrm{CD}_{4} 5^{+}$cells in conjunction with the expression of CD11b in the CNS of mice infected with KC-TMEV and 

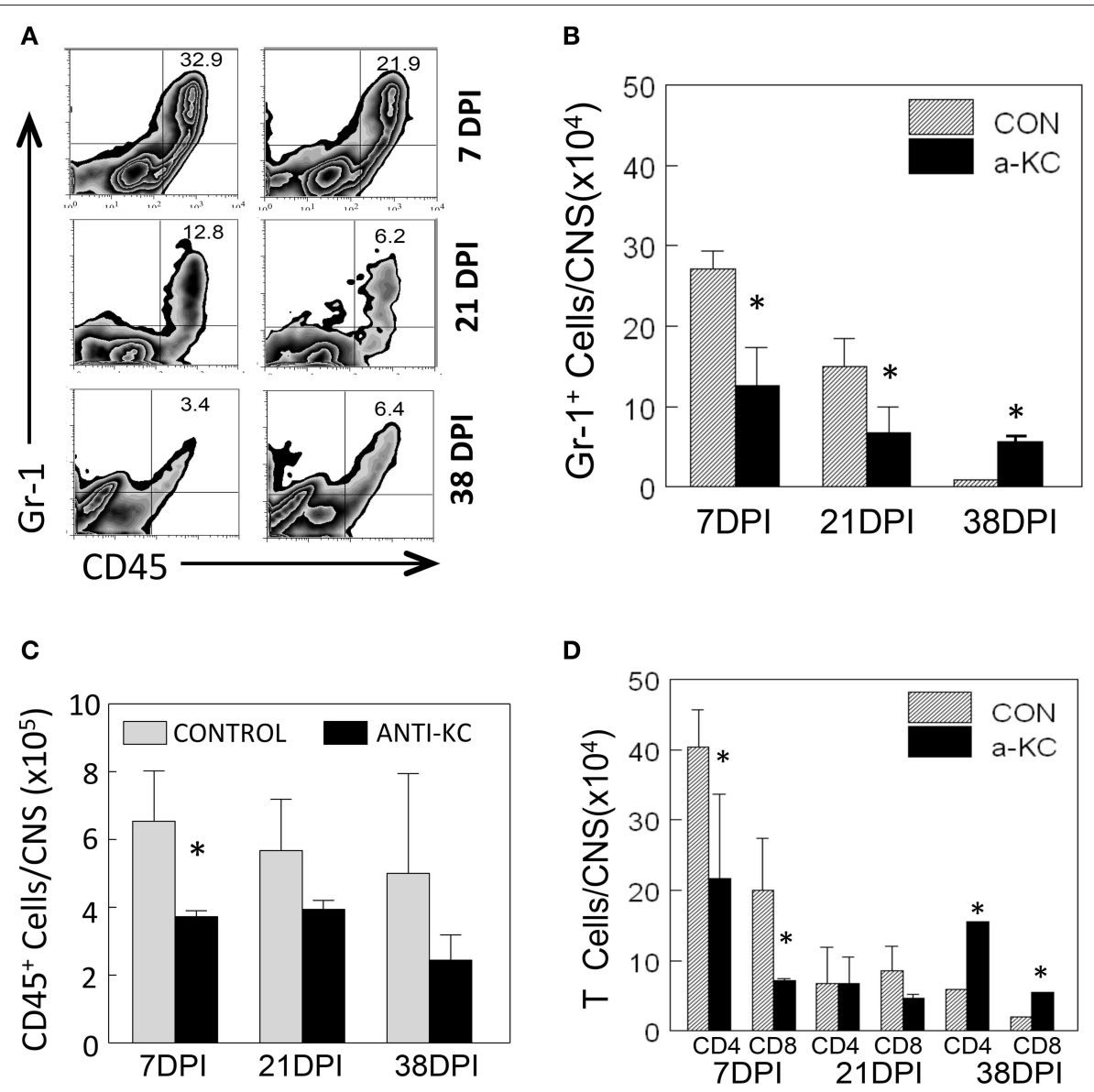

FIGURE 5 | Cellular infiltration into the CNS of mice treated with anti-KC antibody and control mice. (A) The proportions of Gr- $1^{+} \mathrm{CD} 45^{+}$neutrophils in the $\mathrm{CNS}$ of TMEV-infected mice treated with anti-KC and control antibodies were assessed using flow cytometry. (B) The numbers of Gr-1 ${ }^{+} \mathrm{CD} 45^{+}$cells in mice treated with anti-KC antibody compared to control mice at early infection (7 dpi), during disease onset (21 dpi), and after the development of disease were assessed. The overall numbers of $\mathrm{CD}_{4} 5^{+}$cells $(\mathbf{C})$ and $\mathrm{CD}^{+}{ }^{+}$and $\mathrm{CD} 8^{+}$T cells $(\mathbf{D})$ in the antibody-treated mice during the period of viral infection are shown. Values given are the means $( \pm S D)$ of the results from 2 to 3 independent experiments. ${ }^{*} p<0.05$.

HEL-TMEV (Figure 8B). The results indicated that $\mathrm{CD}^{+}{ }^{+} \mathrm{T}$ cells and $\mathrm{CD} 11 \mathrm{~b}^{+} \mathrm{CD} 45^{+}$macrophages, in particular, infiltrated into the CNS at higher levels in the KC-TMEV infected mice. In combination with nearly 2 -fold higher infiltration of overall mononuclear cells and higher proportions in the CNS (Figure 8B), the overall numbers of macrophages $(p=0.0187)$ and CD $4^{+}$T cells $(p=0.0015)$ were 3 to 4 -fold higher in the CNS of KC-TMEV infected mice compared to the control HEL-TMEV infected mice. We also examined IFN- $\gamma$ and IL-17 production in response to the $\mathrm{CD}^{+}{ }^{+}$and $\mathrm{CD} 8^{+} \mathrm{T}$ cell-specific viral epitopes in these infected mice at $8 \mathrm{dpi}$ (Figure 8C). The level of IFN- $\gamma$ production in KC-TMEV infected mice was significantly higher $(p<0.05-0.001)$ than those in the control HEL-TMEV infected mice. In addition, the level of IL-17 production was increased ( $p$ $<0.05)$ in the KC-TMEV infected mice, indicating that these mice, which showed elevated pathogenesis of demyelination, also display elevated pathogenic inflammatory $\mathrm{T}$ cell responses. Therefore, although an excessive level of KC may promote the pathogenesis of the disease, but the lack of $\mathrm{KC}$ can also result in disease pathogenesis because of the failure to recruit cells that are required to protect against viral infection.

\section{DISCUSSION}

TMEV infection into various cell types, including different glial cells and antigen-presenting cells, similar to other viral infections, rapidly induces the production of several dominant chemokines (Palma and Kim, 2001, 2004). KC is one of the most predominant chemokines produced in various glial cell types within hours after TMEV infection (Palma and Kim, 2004; Rubio and Sanz-Rodriguez, 2007). Previously, the effects of some of these chemokines such as CCL5, CCL9 (Ure et al., 2005), and CCL2 (Karpus et al., 2006) on the development of TMEVinduced demyelinating disease were reported. These studies indicated that treatment of mice with anti-chemokine antibodies increased viral loads and promoted the pathogenesis of the disease development. Similarly, other neurotropic virus-induced 


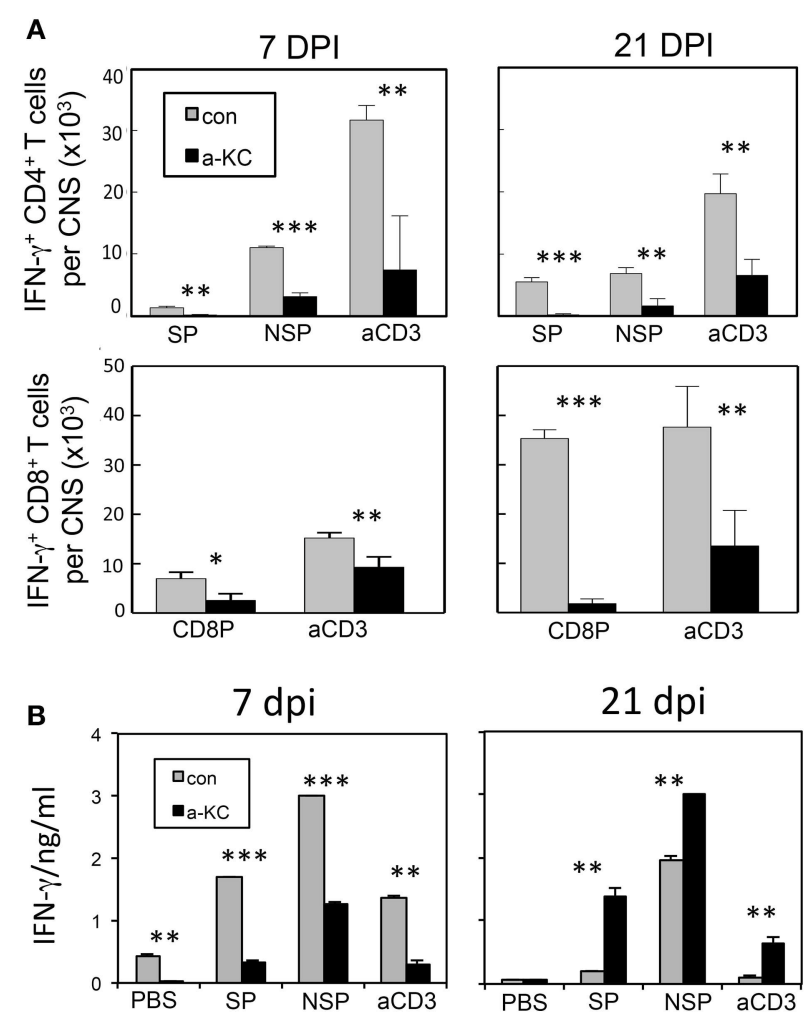

FIGURE 6 | Analysis of $\mathrm{CD}^{+}{ }^{+}$and $\mathrm{CD}^{+}{ }^{+} \mathrm{T}$ cells that produce IFN- $\gamma$ following infection with TMEV. (A) Mononuclear cells from the CNS of mice at 7 and 21 dpi were cultured for $6 \mathrm{~h}$ in the presence of PBS or a mixture of $1 \mu \mathrm{M}$ of viral peptides and assessed the production of intracellular IFN- $\gamma$ using flow cytometry. The data are representative of three independent experiments. (B) Splenocytes from mice at 7 and $21 \mathrm{dpi}$ were cultured for $72 \mathrm{~h}$ in the presence of PBS, a mixture of $1 \mu \mathrm{M}$ viral peptides or anti-CD3/CD28 antibodies. The production of IFN- $\gamma$ in the culture supernatants were assessed using ELISA. Mixtures of CD4 ${ }^{+}$T cell-specific epitopes (SP mix; VP1 233-250, VP2 $74-86$, and VP3 $24-37$; NSP mix, 3D $6-23$ and $3 D_{20}-38$ ) and CD8 ${ }^{+} \mathrm{T}$ cell-specific epitopes (CD8 mix; VP3159-166, VP3 $173-181$, and VP1 11-20) were used. Mixtures of plate-bound anti-CD3 and anti-CD28 antibodies (1 $\mu \mathrm{g}$ each) were used to stimulate pan-T cells. Values given are the means $( \pm S D)$ of the results from triplicate wells. ${ }^{*} p<0.05 ;{ }^{* *} p<0.01 ;{ }^{* *} p<0.001$.

diseases were also investigated and found that these chemokines play a protective role (Hosking et al., 2009). However, very little is known about the role of $\mathrm{KC}$, which is associated with the migration of first defense cell type neutrophils (Zhou et al., 2003) in the pathogenesis of TMEV-induced demyelinating disease. In this study, we have explored the potential role of one of the most abundantly produced chemokine, $\mathrm{KC}$, in the development of TMEV-induced demyelinating disease by utilizing antibodies against $\mathrm{KC}$ and recombinant $\mathrm{KC}-\mathrm{TMEV}$ carrying the $\mathrm{KC}$ gene.

It was interesting to observe that several-fold higher levels of $\mathrm{KC}$ were produced in cells from susceptible SJL mice compared to those from resistant B6 mice following TMEV infection and stimulations with different TLR ligands (Figure 1). These results are consistent with the previous finding that astrocytes derived from susceptible SJL mice but not astrocytes derived from resistant $\mathrm{BALB} / \mathrm{c}$ mice, which are also resistant to TMEV-induced demyelinating disease, produce high levels of $\mathrm{KC}$ following TMEV infection (Rubio and Sanz-Rodriguez, 2007). These findings suggested that excessive production of $\mathrm{KC}$ following viral infection might contribute to the susceptibility of SJL mice to the development of TMEV-induced demyelinating disease, as seen from the effects of IL- $1 \beta$, IFN- $\alpha / \beta$, or TLR3 signaling (Jin et al., 2010, 2011; Kim et al., 2012). The higher levels of KC production upon TMEV infection may reflect the higher levels of viral permissiveness of the cells from susceptible SJL mice compared to the cells from resistant C57BL/6 mice (Jin et al., $2007,2015)$. Interestingly, the production of KC depended on the presence of MyD88 (Figure 2), which is not associated with the major TMEV-induced TLR3 signaling (So et al., 2006; Johnson et al., 2008). Therefore, a secondary TLR or a cytokine signaling following TMEV infection may be involved in the triggering the KC production. It is conceivable that IL-1 and/or IL-18 produced in a MyD88-dependent manner may be associated with the production of KC as shown previously (Adachi et al., 1998; Lee et al., 2015). Because TMEV infection is known to induce the upregulation of other TLRs including TLR2 (Turrin, 2008; So and Kim, 2009) whose signaling depends on the presence of MyD88 (Takeda and Akira, 2004), it is likely that TLR2 signaling upregulated via the TMEV-induced TLR3 activation is associated with $\mathrm{KC}$ production.

Treatment of mice with anti-KC antibodies significantly promoted the pathogenesis of TMEV-induced demyelinating disease and elevated viral loads in the CNS compared to control IgG-treated mice (Figure 3). Therefore, the presence of $\mathrm{KC}$ during the initial viral infection is essential for the protection from the development of TMEV-induced demyelinating disease. Direct assessment of $\mathrm{KC}$ gradient differences in the CNS during viral infections, although technically challenging, may be helpful in understanding the role of $\mathrm{KC}$ in the pathogenesis of demyelinating disease in future studies. The development of clinical signs and high viral loads in the CNS were consistent with histopathological examinations of the spinal cords, which showed increased irregular vacuolation and demyelinating lesions in the white matter of the spinal cords of anti-KC antibody-treated mice compared to the control mice (Figure 4). The TMEV BeAn strain, unlike DA strain, is known to induce minimal to undetectable acute phase disease (Dal Canto and Lipton, 1975; Dal Canto et al., 1996). SJL mice infected with BeAn strain induces a progressive demyelinating disease as early as 12-20 days post-infection depending on the potency of the viral batch and their immune status (Hou et al., 2007, 2009). Therefore, it is most likely that our observed clinical symptoms represent the progression of demyelinating disease, coupled with the histological evidence at $35 \mathrm{dpi}$ (Figure 4). In addition, the infiltration of $\mathrm{Gr}-1^{+} \mathrm{CD} 45^{+}$cells and the overall numbers of $\mathrm{CD}_{4} 5^{+}$cells, including $\mathrm{CD}^{+}{ }^{+}$and $\mathrm{CD}^{+}{ }^{+} \mathrm{T}$ cells, into the CNS was significantly lower in mice treated with anti-KC antibody compared to the control mice at early infection and during disease onset (Figure 5). Consistent with the infiltration of $\mathrm{T}$ cell levels, the protective IFN- $\gamma$-producing $\mathrm{T}$ cell levels in the CNS were also lower in the antibody-treated mice (Figure 6). These results strongly suggest that a low level of KC during viral infection fails to facilitate the migration of sufficient 

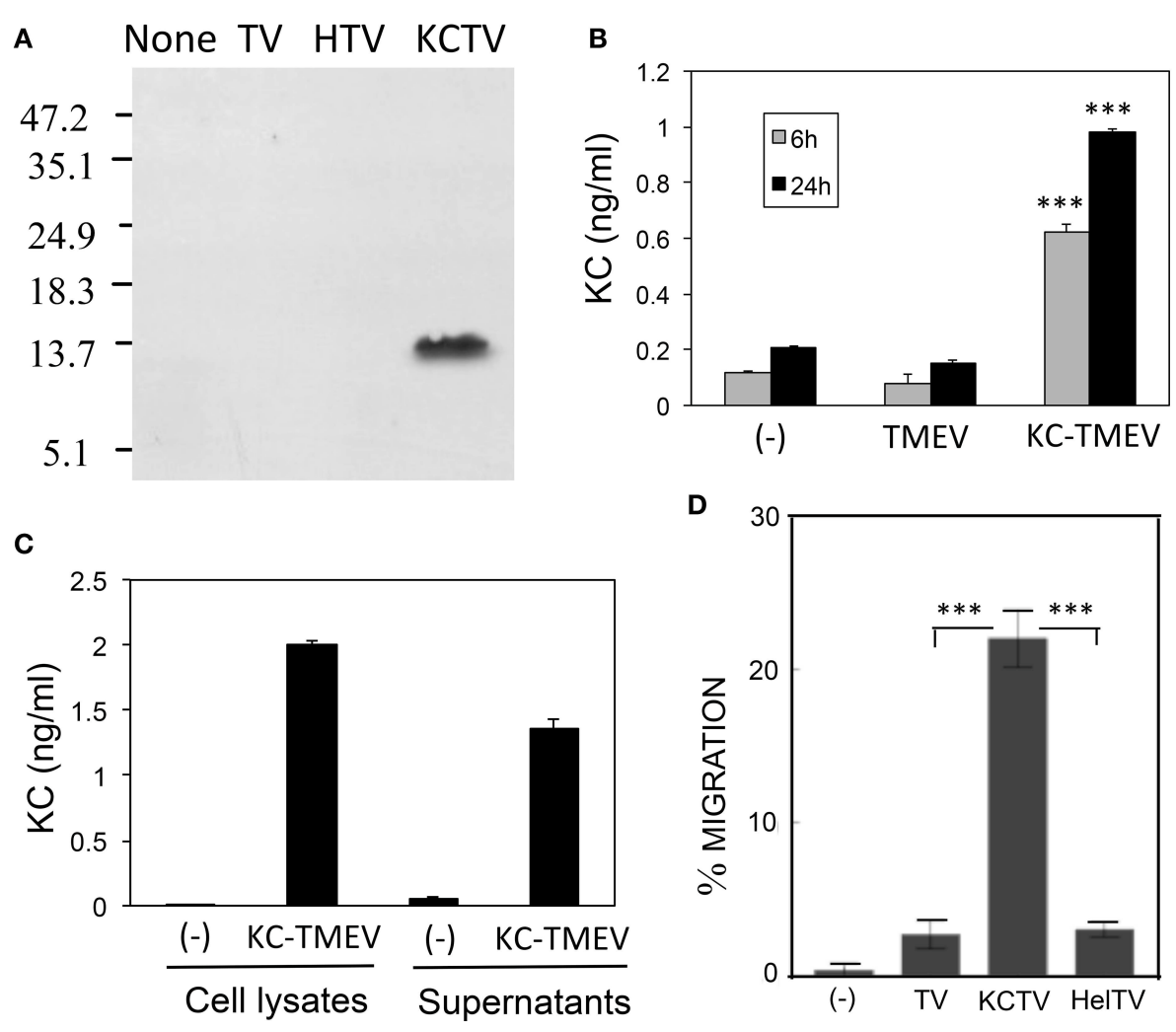

FIGURE 7 | (A) Production of CXCL-1 (KC) following infection (MOI = 10) in BHK cells with control TMEV (TV), control HEL-TMEV (HTV), and KC-TMEV (KCTV) analyzed 24-h post infection with Western blotting. Cell lysates in Tris-buffered saline with 1\% Triton X-100 were separated by electrophoresis, transferred to nitrocellulose membranes, and then analyzed using rabbit anti-KC antibody. A representative result from two similar experiments is shown. (B) BHK cell lysates from triplicate cultures that were mock-infected, or infected with control TMEV or KC-TMEV for 6 and $24 \mathrm{~h}$ were subjected to a mouse KC-specific ELISA (BD, CA). The means $( \pm S D$ ) of the results from triplicate cultures are shown. (C) To further determine whether the KC produced after infection with KC-TMEV remained cell bound or was secreted, culture supernatants and cell lysates of BHK cells mock-infected or infected with KC-TMEV were assessed for the presence of mouse KC using ELISA. The means $( \pm S D$ ) of the results from triplicate cultures are shown. (D) Supernatants of monolayer BHK cells mock-infected or infected with control TMEV or KC-TMEV for $24 \mathrm{~h}$ were overlaid with Boyden chamber membranes containing GFP-expressing peripheral blood neutrophils that were enriched by using negative magnetic sorting. The cultures were incubated for $3 \mathrm{~h}$ and the membranes were flipped over to assess the number of transmigrated cells. An example microscopy image of an experiment is shown. A summary of three transmigration assessments is shown. Values given are the means ( $\pm S D$ ) of the results from three separate experiments. ${ }^{\star \star \star} p<0.001$.

neutrophils and other inflammatory cells into the CNS at the site of viral infection and propagation. These results are consistent with the previous findings with mouse hepatitis virusinduced demyelinating disease following the treatment with antiCCR2 antibody against the CXCL1 receptor (Hosking et al., 2009). Therefore, the presence of $\mathrm{KC}$ at the site of initial viral infection appears to play an important role in the protection against viral pathogenesis by promoting cellular infiltration into the CNS.

To further determine the effects of excessive KC production on the pathogenesis of TMEV, we generated recombinant KCTMEV based on the dL23 TMEV backbone (Calenoff et al., 1995). Western blotting with anti-mouse KC antibodies and mouse KC-specific ELISA on virus-infected BHK cells indicated that the levels of $\mathrm{KC}$ produced in the KC-TMEV infected cells for 6 and $24 \mathrm{~h}$ were several folds higher than that in the cells infected with control HEL-TMEV (Figure 7). The transmigration of purified peripheral blood neutrophils through micropore membranes due to KC production after KC-TMEV infection was also significantly higher in the KC-TMEV infected cells, indicating the intact functionality of $\mathrm{KC}$ produced by the recombinant $\mathrm{KC}-\mathrm{TMEV}$. Therefore, excessive production of $\mathrm{KC}$ following $\mathrm{KC}-\mathrm{TMEV}$ infection is most likely to affect the migration and/or activation of both infected cells and the adjacent cells.

The development of demyelinating disease in SJL mice infected with KC-TMEV was significantly accelerated compared to mice infected with control HEL-TMEV (Figure 8). Thus, the presence of an excessive level of $\mathrm{KC}$ during KC-TMEV infection appears to play a pathogenic role in the development of demyelinating disease. Neutrophils, $\mathrm{T}$ cells, and macrophages infiltrated the CNS at higher levels in the KC-TMEV-infected mice, which showed elevated pathogenesis of demyelination. Interestingly, the KC-TMEV infected mice also displayed elevated inflammatory $\mathrm{T}$ cell responses, which are known to be responsible for the pathogenesis of demyelination (Myoung 


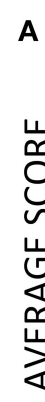

A

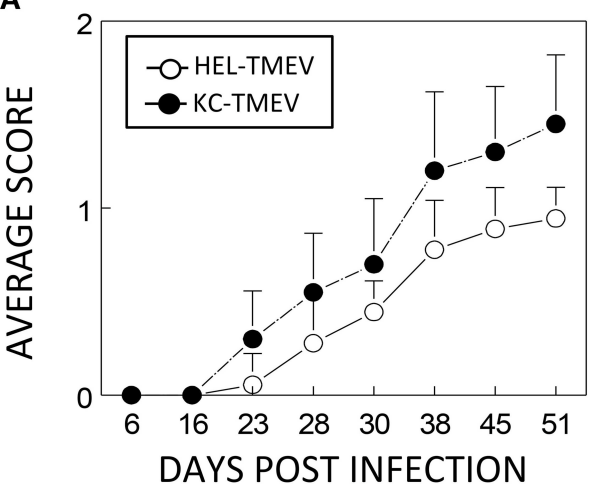

C

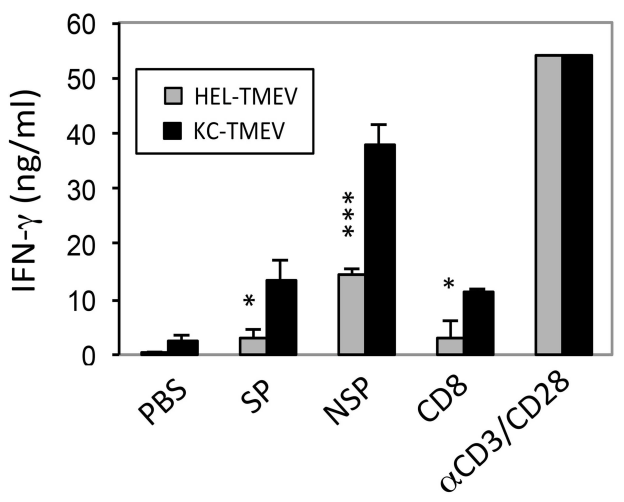

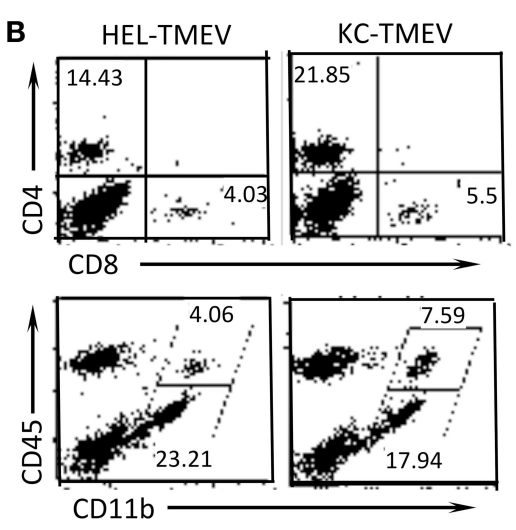

FIGRE 8 | Development of demyelinating disease and T cell responses after infection with KC-TMEV and control HEL-TMEV. (A) SJL mice were infected with KC-TMEV $(n=10)$ or control HEL-TMEV $(n=9)$. The animals were graded for clinical signs as described in the Materials and Methods section. The results are expressed as average clinical scores of animals at the indicated dpi. The two-tailed $p$-value of the two groups based on the paired $t$-test between 23 and 51 dpi was very significant $(p<0.0004)$. (B) Infiltration of CD4 ${ }^{+}$and CD8 ${ }^{+}$T cells and CD45+ CD11 ${ }^{+}$cells into the CNS after infection with KC-TMEV or TMEV (4 dpi) was assessed using flow cytometry. The overall numbers of CD4 ${ }^{+}$T cells $\left[(43.421 \pm 6.585\right.$ vs. $\left.11.339 \pm 2.849) \times 10^{4}\right]$ and macrophages $[(10.627 \pm 3.474$ vs. $2.342 \pm$ 1.426) $\left.\times 10^{4}\right]$ infiltrated in the CNS of KC-TMEV infected mice were significantly higher than those of HEL-TMEV infected mice, respectively. (C) IFN- $\gamma$ and IL-17 levels in the supernatants of the splenic cultures were determined using ELISA. Spleen cells were prepared 8 dpi from SJL mice infected with control HEL-TMEV ( $n=3$ ) or KC-TMEV $(n=3)$. Cells were cultured for $72 \mathrm{~h}$ in the presence of PBS or a mixture of $1 \mu \mathrm{M}$ of the peptides. Mixtures of CD4 ${ }^{+}$T-cell-specific epitopes (SP mix; VP1 $233-250$, VP2 $74-86$, and VP3 $24-37$; NSP mix, 3D $6-23$ and 3D20-38) and CD8 ${ }^{+}$T cell-specific epitopes (CD8 mix; VP3 $159-166$, VP3 $173-181$, and VP1 11-20) were used. $\alpha \mathrm{CD} 3 / \mathrm{CD} 28$ represents plate-bound anti-CD3 and anti-CD28 antibodies (1 $\mu \mathrm{g}$ each) used to stimulate pan-T cells. The culture supernatants were subsequently collected for ELISA. The data are representative of three independent experiments. Values given are the means $( \pm S D)$ of the results from triplicate wells. * $P<0.05$; ${ }^{\star * \star} p<0.001$

et al., 2008). This result is opposite to the effect of $\mathrm{KC}$ on the development of autoimmune demyelinating disease in inducible KC-Tg mice (Omari et al., 2009), which provided protection from the disease development. However, infection of the $\mathrm{Tg}$ mice displaying sustained KC expression with mouse hepatitis virus resulted in increased mortality accompanying elevated neutrophil infiltration induced demyelinating disease (Marro et al., 2016). These results indicates that the role of $\mathrm{KC}$ in the pathogenesis of TMEV-induced demyelinating disease may be dual similar to other virus-induced CNS inflammatory diseases, i.e., its presence is helpful for protection but excessive levels can be pathogenic, similar to the roles of IL-1. We have previously shown that the presence of a high level of IL-1 plays a pathogenic role, whereas the lack of IL-1 signal promotes viral persistence in the spinal cord due to insufficient $\mathrm{T}$ cell activation (Kim et al., 2012). In a similar way, an excessive level of TLR3 signaling contributes to disease pathogenesis, but the presence of the TLR3 signal is required to protect the host from chronic viral infections (Jin et al., 2011).

\section{CONCLUSIONS}

In this study, we first compared the levels of $\mathrm{KC}$, one of the most predominant chemokines upon viral infection, produced after infection with TMEV or stimulation with various TLRs in various cells from susceptible SJL mice and resistant B6 mice. The level of KC produced after infection with TMEV or stimulation with TLRs was significantly higher in cells from susceptible SJL mice than those in cells from resistant B6 mice. In addition, the production of $\mathrm{KC}$ was completely dependent on the presence of MyD88, unlike the production of IL-6. This result strongly suggests that the pathways associated with the 
production of $\mathrm{KC}$ is distinct from that of IL-6, which is one of the most important cytokine affecting the pathogenesis of viral demyelinating disease (Rodriguez et al., 1994; Hou et al., 2009, 2014; Jin et al., 2013). We further investigated the potential role of $\mathrm{KC}$ in the progression of TMEV-induced demyelinating disease. We have either reduced the level of $\mathrm{KC}$ with anti$\mathrm{KC}$ antibody treatment or supplied an excessive level of $\mathrm{KC}$ during viral infection with recombinant KC-TMEV producing KC. Our results indicated that the presence of a certain level of this chemokine is essential for the influx of cells into the CNS for protection, but an excessive amount can be harmful because of the induction of inflammation during virally induced chronic demyelinating disease. Our approach of utilizing the recombinant virus expressing the chemokine is particularly important because it allows the chemokine to be targeted at the infection site at a level proportional to viral replication without any further manipulation. A variety of biologically active small molecules, such as IL-1, may also be applied in the construction of recombinant viruses to investigate the function and role of these molecules in the pathogenesis of chronic virally induced inflammatory diseases.

\section{REFERENCES}

Adachi, O., Kawai, T., Takeda, K., Matsumoto, M., Tsutsui, H., Sakagami, M., et al. (1998). Targeted disruption of the MyD88 gene results in loss of IL-1- and IL-18-mediated function. Immunity 9, 143-150. doi: 10.1016/S1074-7613(00)80596-8

Aubert, C., Chamorro, M., and Brahic, M. (1987). Identification of Theiler's virus infected cells in the central nervous system of the mouse during demyelinating disease. Microb. Pathog. 3, 319-326. doi: 10.1016/0882-4010(87)90002-7

Calenoff, M. A., Badshah, C. S., Dal Canto, M. C., Lipton, H. L., and Rundell, M. K. (1995). The leader polypeptide of Theiler's virus is essential for neurovirulence but not for virus growth in BHK cells. J. Virol. 69, 5544-5549.

Clatch, R. J., Lipton, H. L., and Miller, S. D. (1987). Class II-restricted T cell responses in Theiler's murine encephalomyelitis virus (TMEV)-induced demyelinating disease. II. Survey of host immune responses and central nervous system virus titers in inbred mouse strains. Microb. Pathog. 3, 327-337. doi: 10.1016/0882-4010(87)90003-9

Cotter, M. J., Norman, K. E., Hellewell, P. G., and Ridger, V. C. (2001). A novel method for isolation of neutrophils from murine blood using negative immunomagnetic separation. Am. J. Pathol. 159, 473-481. doi: 10.1016/S0002-9440(10)61719-1

Dal Canto, M. C., and Lipton, H. L. (1975). Primary demyelination in Theiler's virus infection. an ultrastructural study. Lab. Invest. 33, 626-637.

Dal Canto, M. C., Kim, B. S., Miller, S. D., and Melvold, R. W. (1996). Theiler's Murine encephalomyelitis virus (TMEV)-induced demyelination: a model for human multiple sclerosis. Methods 10, 453-461. doi: 10.1006/meth.1996.0123

Farnand, A. W., Eastman, A. J., Herrero, R., Hanson, J. F., Mongovin, S., Altemeier, W. A., et al. (2011). Fas activation in alveolar epithelial cells induces KC (CXCL1) release by a MyD88-dependent mechanism. Am. J. Respir. Cell Mol. Biol. 45, 650-658. doi: 10.1165/rcmb.2010-0153OC

Gho, Y. S., Kleinman, H. K., and Sosne, G. (1999). Angiogenic activity of human soluble intercellular adhesion molecule-1. Cancer Res. 59, 5128-5132.

Guerrero, A. T., Cunha, T. M., Verri, W. A. Jr., Gazzinelli, R. T., Teixeira, M. M., Cunha, F. Q., et al. (2012). Toll-like receptor 2/MyD88 signaling mediates zymosan-induced joint hypernociception in mice: participation of TNF-alpha, IL-1beta and CXCL1/KC. Eur. J. Pharmacol. 674, 51-57. doi: 10.1016/j.ejphar.2011.10.023

Hosking, M. P., Liu, L., Ransohoff, R. M., and Lane, T. E. (2009). A protective role for ELR+ chemokines during acute viral encephalomyelitis. PLoS Pathog. 5:e1000648. doi: 10.1371/journal.ppat.1000648

\section{ETHICS STATEMENT}

Experiments using animals were conducted according to the permission (\#2011-1316 for Byung Kim) of the Animal Care and Use Committee at Northwestern University.

\section{AUTHOR CONTRIBUTIONS}

MK carried out the initial experiments determining the expression of KC and IL- 6 genes in cells infected with TMEV or stimulated with TLR ligands. Also, MK generated KC-TMEV and HEL-TMEV recombinant viruses and characterized the viruses. $\mathrm{MK}$ and YJ conducted the animal experiments including the disease development and various immune assays. BK directed the experiments and prepared the manuscript with YJ.

\section{FUNDING}

This work was supported by the United States Public Health Service Grants (RO1 NS28752 and RO1 NS33008) and by a grant from the National Multiple Sclerosis Society (RG 4001-A6).

Hou, W., Jin, Y. H., Kang, H. S., and Kim, B. S. (2014). Interleukin-6 (IL-6) and IL17 synergistically promote viral persistence by inhibiting cellular apoptosis and cytotoxic T cell function. J. Virol. 88, 8479-8489. doi: 10.1128/JVI.00724-14

Hou, W., Kang, H. S., and Kim, B. S. (2009). Th17 cells enhance viral persistence and inhibit T cell cytotoxicity in a model of chronic virus infection. J. Exp. Med. 206, 313-328. doi: 10.1084/jem.20082030

Hou, W., So, E. Y., and Kim, B. S. (2007). Role of dendritic cells in differential susceptibility to viral demyelinating disease. PLoS Pathog. 3:e124. doi: 10.1371/journal.ppat.0030124

Jin, Y. H., Hou, W., Kang, H. S., Koh, C. S., and Kim, B. S. (2013). The role of interleukin- 6 in the expression of PD-1 and PDL-1 on central nervous system cells following infection with Theiler's murine encephalomyelitis virus. J. Virol. 87, 11538-11551. doi: 10.1128/JVI.01967-13

Jin, Y. H., Hou, W., Kim, S. J., Fuller, A. C., Kang, B., Goings, G., et al. (2010). Type I interferon signals control Theiler's virus infection site, cellular infiltration and T cell stimulation in the CNS. J. Neuroimmunol. 226, 27-37. doi: 10.1016/j.jneuroim.2010.05.028

Jin, Y. H., Kaneyama, T., Kang, M. H., Kang, H. S., Koh, C. S., and Kim, B. S. (2011). TLR3 signaling is either protective or pathogenic for the development of Theiler's virus-induced demyelinating disease depending on the time of viral infection. J. Neuroinflammation 8:178. doi: 10.1186/1742-2094-8-178

Jin, Y. H., Kang, H. S., Hou, W., Meng, L., and Kim, B. S. (2015). The level of viral infection of antigen-presenting cells correlates with the level of development of Theiler's murine encephalomyelitis virus-induced demyelinating disease. J. Virol. 89, 1867-1878. doi: 10.1128/JVI.02471-14

Jin, Y. H., Kim, S. J., So, E. Y., Meng, L., Colonna, M., and Kim, B. S. (2012). Melanoma differentiation-associated gene 5 is critical for protection against Theiler's virus-induced demyelinating disease. J. Virol. 86, 1531-1543. doi: 10.1128/JVI.06457-11

Jin, Y. H., Mohindru, M., Kang, M. H., Fuller, A. C., Kang, B., Gallo, D., et al. (2007). Differential virus replication, cytokine production, and antigen-presenting function by microglia from susceptible and resistant mice infected with Theiler's virus. J. Virol. 81, 11690-11702. doi: 10.1128/JVI.01 034-07

Johnson, A. C., Li, X., and Pearlman, E. (2008). MyD88 functions as a negative regulator of TLR3/TRIF-induced corneal inflammation by inhibiting activation of c-Jun N-terminal kinase. J. Biol. Chem. 283, 3988-3996. doi: 10.1074/jbc.M707264200

Karpus, W. J., Kennedy, K. J., Fife, B. T., Bennett, J. L., Dal Canto, M. C., Kunkel, S. L., et al. (2006). Anti-CCL2 treatment inhibits Theiler's murine 
encephalomyelitis virus-induced demyelinating disease. J. Neurovirol. 12, 251-261. doi: 10.1080/13550280600873819

Kerstetter, A. E., Padovani-Claudio, D. A., Bai, L., and Miller, R. H. (2009). Inhibition of CXCR2 signaling promotes recovery in models of multiple sclerosis. Exp. Neurol. 220, 44-56. doi: 10.1016/j.expneurol.2009.07.010

Kim, B. S., Jin, Y. H., Meng, L., Hou, W., Kang, H. S., Park, H. S., et al. (2012). IL-1 signal affects both protection and pathogenesis of virusinduced chronic CNS demyelinating disease. J. Neuroinflammation 9:217. doi: 10.1186/1742-2094-9-217

Kim, B. S., Lyman, M. A., Kang, B. S., Kang, H. K., Lee, H. G., Mohindru, M., et al. (2001). Pathogenesis of virus-induced immune-mediated demyelination. Immunol. Res. 24, 121-130. doi: 10.1385/IR:24:2:121

Lee, Y. S., Yang, H., Yang, J. Y., Kim, Y., Lee, S. H., Kim, J. H., et al. (2015). Interleukin-1 (IL-1) signaling in intestinal stromal cells controls KC/ CXCL1 secretion, which correlates with recruitment of IL-22- secreting neutrophils at early stages of Citrobacter rodentium infection. Infect. Immun. 83, 3257-3267. doi: 10.1128/IAI.00670-15

Lehrich, J. R., Arnason, B. G., and Hochberg, F. H. (1976). Demyelinative myelopathy in mice induced by the DA virus. J. Neurol. Sci. 29, 149-160. doi: 10.1016/0022-510X(76)90167-2

Leibowitz, J. L., and Rodriguez, M. (1983). Antigenic variants are not selected during persistent infection with Theiler's virus. Infect. Immun. 41, 440-442.

Lipton, H. L., and Dal Canto, M. C. (1976). Theiler's virus-induced demyelination: prevention by immunosuppression. Science 192, 62-64. doi: 10.1126/science.176726

Lipton, H. L., Kumar, A. S., and Trottier, M. (2005). Theiler's virus persistence in the central nervous system of mice is associated with continuous viral replication and a difference in outcome of infection of infiltrating macrophages versus oligodendrocytes. Virus Res. 111, 214-223. doi: 10.1016/j.virusres.2005.04.010

Lorch, Y., Friedmann, A., Lipton, H. L., and Kotler, M. (1981). Theiler's murine encephalomyelitis virus group includes two distinct genetic subgroups that differ pathologically and biologically. J. Virol. 40, 560-567.

Marro, B. S., Grist, J. J., and Lane, T. E. (2016). Inducible expression of CXCL1 within the central nervous system amplifies viral-induced demyelination. J. Immunol. 196, 1855-1864. doi: 10.4049/jimmunol.1501802

Mazzoni, A., Bronte, V., Visintin, A., Spitzer, J. H., Apolloni, E., Serafini, P., et al. (2002). Myeloid suppressor lines inhibit T cell responses by an NO-dependent mechanism. J. Immunol. 168, 689-695. doi: 10.4049/jimmunol.168.2.689

Myoung, J., Bahk, Y. Y., Kang, H. S., Dal Canto, M. C., and Kim, B. S. (2008). Anticapsid immunity level, not viral persistence level, correlates with the progression of Theiler's virus-induced demyelinating disease in viral P1transgenic mice. J. Virol. 82, 5606-5617. doi: 10.1128/JVI.02442-07

Omari, K. M., Lutz, S. E., Santambrogio, L., Lira, S. A., and Raine, C. S. (2009). Neuroprotection and remyelination after autoimmune demyelination in mice that inducibly overexpress CXCL1. Am. J. Pathol. 174, 164-176. doi: 10.2353/ajpath.2009.080350

Palma, J. P., and Kim, B. S. (2001). Induction of selected chemokines in glial cells infected with Theiler's virus. J. Neuroimmunol. 117, 166-170. doi: 10.1016/S0165-5728(01)00326-5

Palma, J. P., and Kim, B. S. (2004). The scope and activation mechanisms of chemokine gene expression in primary astrocytes following infection with Theiler's virus. J. Neuroimmunol. 149, 121-129. doi: 10.1016/j.jneuroim.2003.12.025

Pullen, L. C., Park, S. H., Miller, S. D., Dal Canto, M. C., and Kim, B. S. (1995). Treatment with bacterial LPS renders genetically resistant C57BL/6 mice susceptible to Theiler's virus-induced demyelinating disease. J. Immunol. $155,4497-4503$.

Robinson, S., Tani, M., Strieter, R. M., Ransohoff, R. M., and Miller, R. H. (1998). The chemokine growth-regulated oncogene-alpha promotes spinal cord oligodendrocyte precursor proliferation. J. Neurosci. 18, 10457-10463.
Rodriguez, M., Pavelko, K. D., McKinney, C. W., and Leibowitz, J. L. (1994). Recombinant human IL-6 suppresses demyelination in a viral model of multiple sclerosis. J. Immunol. 153, 3811-3821.

Rubio, N., and Sanz-Rodriguez, F. (2007). Induction of the CXCL1 (KC) chemokine in mouse astrocytes by infection with the murine encephalomyelitis virus of Theiler. Virology 358, 98-108. doi: 10.1016/j.virol.2006. 08.003

Skias, D. D., Kim, D. K., Reder, A. T., Antel, J. P., Lancki, D. W., and Fitch, F. W. (1987). Susceptibility of astrocytes to class I MHC antigen-specific cytotoxicity. J. Immunol. 138, 3254-3258.

So, E. Y., and Kim, B. S. (2009). Theiler's virus infection induces TLR3-dependent upregulation of TLR2 critical for proinflammatory cytokine production. Glia 57, 1216-1226. doi: 10.1002/glia.20843

So, E. Y., Kang, M. H., and Kim, B. S. (2006). Induction of chemokine and cytokine genes in astrocytes following infection with Theiler's murine encephalomyelitis virus is mediated by the Toll-like receptor 3. Glia 53, 858-867. doi: 10.1002/glia.20346

Soehnlein, O., and Lindbom, L. (2010). Phagocyte partnership during the onset and resolution of inflammation. Nat. Rev. Immunol. 10, 427-439. doi: $10.1038 /$ nri2779

Takeda, K., and Akira, S. (2004). TLR signaling pathways. Semin. Immunol. 16, 3-9. doi: 10.1016/j.smim.2003.10.003

Tsai, H. H., Frost, E., To, V., Robinson, S., Ffrench-Constant, C., Geertman, R., et al. (2002). The chemokine receptor CXCR2 controls positioning of oligodendrocyte precursors in developing spinal cord by arresting their migration. Cell 110, 373-383. doi: 10.1016/S0092-8674(02)00838-3

Turrin, N. P. (2008). Central nervous system Toll-like receptor expression in response to Theiler's murine encephalomyelitis virus-induced demyelination disease in resistant and susceptible mouse strains. Virol. J. 5:154. doi: 10.1186/1743-422X-5-154

Ure, D. R., Lane, T. E., Liu, M. T., and Rodriguez, M. (2005). Neutralization of chemokines RANTES and MIG increases virus antigen expression and spinal cord pathology during Theiler's virus infection. Int. Immunol. 17, 569-579. doi: $10.1093 /$ intimm/dxh236

Yauch, R. L., Palma, J. P., Yahikozawa, H., Koh, C. S., and Kim, B. S. (1998). Role of individual T-cell epitopes of Theiler's virus in the pathogenesis of demyelination correlates with the ability to induce a Th1 response. J. Virol. 72, 6169-6174.

Yona, S., Hayhoe, R., and Avraham-Davidi, I. (2010). Monocyte and neutrophil isolation and migration assays. Curr. Protoc. Immunol. Chapter 14:Unit 14.15. doi: 10.1002/0471142735.im1415s88

Zhang, L., Sato, S., Kim, J. I., and Roos, R. P. (1995). Theiler's virus as a vector for foreign gene delivery. J. Virol. 69, 3171-3175.

Zheng, L., Calenoff, M. A., and Dal Canto, M. C. (2001). Astrocytes, not microglia, are the main cells responsible for viral persistence in Theiler's murine encephalomyelitis virus infection leading to demyelination. J. Neuroimmunol. 118, 256-267. doi: 10.1016/S0165-5728(01)00338-1

Zhou, J., Stohlman, S. A., Hinton, D. R., and Marten, N. W. (2003). Neutrophils promote mononuclear cell infiltration during viral-induced encephalitis. J. Immunol. 170, 3331-3336. doi: 10.4049/jimmunol.170. 6.3331

Conflict of Interest Statement: The authors declare that the research was conducted in the absence of any commercial or financial relationships that could be construed as a potential conflict of interest.

Copyright (c) 2018 Kang, Jin and Kim. This is an open-access article distributed under the terms of the Creative Commons Attribution License (CC BY). The use, distribution or reproduction in other forums is permitted, provided the original author(s) or licensor are credited and that the original publication in this journal is cited, in accordance with accepted academic practice. No use, distribution or reproduction is permitted which does not comply with these terms. 